\title{
Socialización bilingüe infantil en Galicia: secuencias conversacionais de cha- mada de atención nunha aula de educación infantil
}

\author{
Marta Díaz-Ferro ${ }^{1}$
}

Recibido: 14 de xaneiro de 2019 / Aceptado: 14 de outubro de 2019

Resumo. O traballo que se presenta a continuación aborda a socialización bilingüe infantil nunha aula de Educación Infantil na cidade galega de Vigo, zona maioritariamente castelán-falante; os nenos, un total de vinte cinco, reciben nesta clase un gran input en lingua galega, código base empregado pola mestra, con alternancias en castelán. Neste artigo centrarémonos nun grupo de secuencias conversacionais que teñen lugar durante unha das rutinas máis importantes da xornada escolar, coñecida como Tempo de asemblea; a importancia deste espazo reside en que as tarefas de alfabetización e organización do resto da xornada teñen lugar neste tempo. Dentro destas tarefas atopamos unha serie de interaccións catalogadas como chamadas de atención da mestra cara aos nenos e é nesas secuencias conversacionais nas que fixamos a nosa atención. O principal obxectivo do traballo consiste en analizar as ditas secuencias e comprobar os distintos usos que delas fai a mestra, que funcións lles outorga en relación coas diferentes situacións vividas na aula. A principal conclusión á que chegamos despois da análise realizada é que existe unha diminución deste tipo de interaccións debido á evolución positiva no comportamento dos nenos: estes van crecendo e interiorizando máis correctamente as pautas de comportamento que esixe cada momento da xornada escolar, concretamente este Tempo de asemblea.

Palabras chave: socialización; bilingüismo infantil; escola; chamadas atención; etnografía interaccional.

\section{[es] Socialización bilingüe infantil en Galicia: secuencias conversacionales de lla- mada de atención en una aula de educación infantil}

Resumen. El trabajo que se presenta a continuación aborda la socialización bilingüe infantil en un aula de Educación Infantil en la ciudad gallega de Vigo (Galicia), zona mayoritariamente castellano-hablante; los niños, un total de veinticinco, reciben en esta clase un gran input en lengua gallega, código base empleado por la profesora, con alternancias en castellano. En este artículo nos centramos en un grupo de secuencias conversacionales que tienen lugar durante una de las rutinas más importantes de la jornada escolar, conocida como Tempo de asemblea; la importancia de este tiempo reside en que las tareas de alfabetización y organización del resto de la jornada tienen lugar en este espacio. Dentro de estas tareas encontramos una serie de interacciones catalogadas como llamadas de atención de la maestra hacia los niños y es en esas secuencias conversacionales en las que fijamos nuestra atención. El principal objetivo de este trabajo consiste en analizar dichas secuencias y comprobar los distintos usos que hace de ellas la profesora, qué funciones les otorga en relación con las diferentes situaciones vividas en el aula. La principal conclusión a la que llegamos después del análisis realizado es que existe una disminución de este tipo de interacciones debido a la evolución positiva del comportamiento de los niños: estos van creciendo e interiorizando más correctamente las pautas comportamentales que exige cada momento de la jornada escolar, concretamente de este Tempo de asemblea.

Palabras clave: socialización; bilingüismo infantil; escuela; llamadas de atención; etnografía interaccional.

\section{[en] Bilingual Children Socialization in Galicia: Conversational Sequences of Call for Attention in an Early Childhood Education Classroom}

Abstract. This paper refers on bilingual child socialization in a classroom of early childhood education in the city of Vigo (Galicia), mainly a Spanish-speaking area; the 25 children in this classroom receive a great input in Galician language, the basic code used by the teacher, with code switching to Spanish. This article is focus on a group of conversational sequences that take place during one of the most important routines of the school day, known as

1 Universidade de Vigo, Departamento de Filoloxía Galega e Latina.

Correo-e: martadiaz@uvigo.es 
Tempo de asemblea; the importance of this session lies in the literacy and organization tasks conducted during it. Among these tasks, this paper concentrates on a series of interactions named calls to attention from the teacher to the children. The aim of this paper is to analyse those sequences and check the different uses the teacher made of them, what functions she attributes them depending on the different situations arising during the school day. The results point out there is a decrease in this type of interaction due to the positive evolution in the children's behaviour: they grow up, and they learn how to internalize the behavioural patterns required at every moment of the school day, specifically during this Tempo de asemblea.

Keywords: Socialization; Child Bilingualism; School; Attention Calls; Interactional Ethnography.

Sumario. 1. Introdución. 2. Tempo de asemblea. 2.1. Tempo de asemblea no curso de 4 anos. 2.2. Tempo de asemblea no curso de 5 anos. 3. Análise dos datos. 3.1. Marcador de distancia. 3.2. Exclusión do interlocutor. 3.3. Marcador da intensidade. 3.4. Préstamos frecuentes. 4. Conclusións. 5. Referencias bibliográficas.

Como citar: Díaz-Ferro, M. (2019): “Socialización bilingüe infantil en Galicia: secuencias conversacionais de chamada de atención nunha aula de educación infantil", en Madrygal. Revista de Estudios Gallegos 22, pp. 259-267.

\section{Introdución}

O traballo presentado nesta comunicación pertence á miña tese doutoral en curso sobre a socialización bilingüe infantil (Ochs e Schieffelin 1995, Ely e Berko Gleason 1996, Kulick e Schieffelin 2006; Duranti, Ochs e Schieffelin 2014) nunha escola pública da cidade de Vigo (Galicia); unha zona de fala maiormente castelán, na que os nenos reciben un grande estímulo en lingua galega.

Para analizar o ambiente en que estes nenos son escolarizados situámonos a carón da teoría da interacción social, postulada por Vygotsky nos anos vinte, debido á importancia de todo o que rodea ao falante á hora de atender ao seu comportamento, dende unha perspectiva lingüística e de análise do discurso.

O traballo de campo foi realizado ao longo de dous cursos escolares (2015-2016 e 20162017) atendendo á mesma clase de Educación Infantil, 4 e 5 anos respectivamente, no colexio público Alfonso D. Rodríguez Castelao; en total a clase consta de vinte cinco nenos e nenas dos cales só dous proveñen de familias bilingües, galego-castelán. A mestra, maiormente castelán-falante, emprega o código galego, aínda que con alternancias en castelán, como lingua vehicular durante a xornada escolar con estes nenos.
A metodoloxía empregada consistiu nunha observación etnográfica semi-participante con notas etnográficas tomadas no momento e gravacións de audio dunha das rutinas escolares máis importantes, da que falaremos no seguinte apartado; estas gravacións foron posteriormente transcritas e analizadas en detalle dende unha perspectiva interpretativo-interaccional.

Para esta comunicación concreta o total de secuencias conversacionais empregadas foi de 52,34 pertencentes ao curso de 4 anos e 18 ao de 5 anos; atendemos concretamente ás secuencias nas que a mestra chama a atención aos nenos debido ao seu mal comportamento ou a outras circunstancias, como iremos vendo, e prestaremos atención ao modo en que a mestra emprega as estratexias discursivas para acadar o seu obxectivo: reacción positiva por parte dos nenos e poder continuar co normal desenvolvemento da clase.

A continuación pasaremos a explicar en detalle en que consiste a rutina escolar de onde foron obtidos os datos que posteriormente analizaremos, xusto antes das conclusións acadadas ata o momento.

\section{Tempo de asemblea}

A xornada escolar ten comezo ás 9 horas da mañá, ata as 14 horas, cun recreo de media hora; cando soa o timbre, os nenos entran na clase e deixan as mochilas nunhas caixas de plástico que hai nun recuncho da aula e os abrigos en cadanseu colgadoiro, de onde recollen o mandil; cada un ten o seu, e o poñen. Unha vez xa vestidos como deben estar, sentan, cada neno enriba dunha pegatina en forma de punto que está pegada no chan, formando un semicírculo nunha zona da aula que denominan asamblea; a mestra senta nunha cadeira fronte a eles, de costas aos encerados. Os nenos deben cumprir unhas normas de comportamento e de como sentar nesta asemblea: coas pernas cruzadas e os brazos enriba destas; existe unha diferenza entre o curso escolar de 4 e de 5 anos: no primeiro deles os nenos podían sentar en calquera sitio desa zona, sempre e cando estivesen enriba dun punto; no curso de 5 anos os sitios eran fixos, é dicir, a comezos do ano cada neno, vixiado pola mestra, colocou unha pegatina vermella en forma de círculo co seu nome escrito para marcar cal ía ser o seu sitio ao longo de todo o curso, agás cando a mestra, polo xeral por motivos de comportamento, decidía cambiar a algún neno de lugar. 
Unha vez que están todos ben sentados e en silencio comeza o que denominan o Tempo de asemblea, esta rutina escolar tan importante da que obtivemos as secuencias que posteriormente analizaremos. A partires de aquí falaremos primeiro desta rutina no curso de 4 anos e seguidamente da mesma no de 5 anos, debido a que existen certas diferenzas entre ambas.

\subsection{Tempo de asemblea no curso de 4 anos}

Unha vez que os nenos están sentados a mestra dá comezo a esta rutina escribindo no encerado en letras maiúsculas e en lingua galega a data do día co seguinte formato: día da semana, día do mes, mes e ano; a continuación teñen lugar as tres partes fundamentais da mesma: 1) unha vez escollido o neno ou nena encargado do día, realizan no aire, co dedo índice, a pictografía dese nome; 2) os nenos, por quendas asignadas pola mestra, propoñen palabras que comezan pola letra inicial dese nome; 3) a mestra, outorgando novamente as quendas, indícalles aos nenos que palabras deben rodear, das escritas anteriormente no encerado.

Unha vez que finalizan estas tres pequenas actividades dentro desta rutina, a mestra aproveita para facer os anuncios pertinentes e organizar o resto da xornada escolar, así como, en ocasións, a propia semana.

\subsection{Tempo de asemblea no curso de 5 anos}

No curso de 5 anos, unha vez que os nenos están sentados xa na posición anteriormente indicada, a mestra escribe no encerado, en letras maiúsculas e minúsculas e en lingua galega, a data do día co formato xa empregado no curso anterior; feito isto, teñen comezo as tres partes fundamentais da rutina que nos interesa: 1) o neno ou nena encargado escribe no encerado o seu propio nome, podendo escoller entre facelo en letras maiúsculas ou minúsculas (ou mesmo ambas); 2) os nenos, guiados pola mestra, realizan no aire co dedo índice a pictografía das letras dese nome; 3) por quendas outorgadas pola mestra, os nenos van propoñendo palabras que comecen pola letra ou sílaba inicial dese nome e, en ocasións, despois realizan un pequeno xogo denominado a Maxia coas Letras, no que os nenos van creando palabras coas letras do nome co que traballaron anteriormente.

A continuación pasaremos a analizar en detalle as secuencias obxecto de estudo deste traballo, as secuencias de chamada de atención que tiveron lugar ao longo desta rutina, en ambos cursos.

\section{Análise dos datos}

Primeiramente debemos sinalar algúns aspectos relacionados coa presentación dos fragmentos para poder entender mellor como interpretalos sen caer en erros.

Nos fragmentos que amosamos empregamos distintos tipos de letra, acorde co seguinte patrón: a negriña fai referencia ao código castelán, a itálica queda reservada para os termos que son ambiguos, é dicir, que pertencen tanto ao galego como ao castelán e, por último, as palabras que corresponden ao galego están representadas en letra normal. Ademais, os nomes dos nenos e nenas aparecen substituídos por tantas $<\mathrm{x}>$ coma sílabas teñan no seu nome, para preservar as súas identidades; no caso da mestra, é referida sempre como 'M.'

Como dixemos, neste traballo o obxecto concreto de estudo son as secuencias que denominamos 'chamada de atención' por parte da mestra cara aos nenos, en ambos cursos, observando como esta emprega diversas estratexias comunicativas con tal finalidade e en que tipo de actividades e casos se dan.

Unha das estratexias que atopamos ao longo destas chamadas de atención é o cambio de código (code-switching) do que fai uso a mestra e ao que atenderemos máis especialmente. Este fenómeno, definido por Grosjean como "the alternate use of two languages, that is, the speaker makes a complete shift to another language for a word, phrase, or sentence and then reverts back to the base language" (2010: 51-52), aparece de forma repetida no discurso xeral da mestra, pero nos casos das chamadas de atención achega, ademais, unha intención propia: ou ben marcar unha distancia entre o neno interpelado e a mestra, ou ben excluír a ese neno do conxunto da clase, debido a que se está comportando mal, ou ben para intensificar esa chamada de atención (Grosjean 2010). Ademais, a mestra combina este cambio de código con outras formas, a nivel léxico, tamén tanto en lingua castelá coma en lingua galega, como poden ser os diminutivos (para unha información máis exhaustiva dos usos destas formas no curso de 4 anos, véxase Díaz-Ferro 2018).

Como indicamos anteriormente na introdución deste traballo, o total de secuencias tidas en conta para analizar foi de 52, das cales 34 pertencen ao primeiro dos cursos e 18 ao 
segundo, ao de 5 anos. Dentro do tipo de actividades nas que teñen lugar estas secuencias, a meirande parte delas danse cando os nenos teñen que propoñer palabras que comecen pola letra inicial do nome do neno encargado do día e durante a actividade conxunta de realizar no aire co dedo índice a pictografía das letras do nome do neno encargado.

Visto o contexto xeral no que se desenvolven estas secuencias, nalgúns casos subsecuencias por estaren dentro de secuencias máis xerais, imos analizalas tendo en conta a finalidade observada no cambio de código por parte da mestra.

\subsection{Marcador de distancia}

Neste apartado imos prestar atención a aquelas subsecuencias nas que a finalidade da mestra ao cambiar de código é a de marcar distancia entre ela e o seu interlocutor, polo xeral un dos nenos da clase. Deste caso temos os fragmentos que amosamos a continuación e que pertencen ao curso de 4 anos.

- Fragmento 1: 4 anos

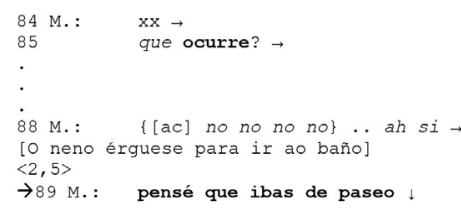

Neste primeiro fragmento, a chamada de atención ten lugar durante a realización pictográfica das letras do nome do neno encargado do día. Un dos nenos interrompe a actividade erguéndose e pasando polo medio da zona delimitada como de asemblea, infrinxindo así unha das normas: non erguerse nin pasar polo medio desta zona sen permiso. A mestra chámalle a atención focalizando esta mediante o emprego do seu nome propio (1.84) coa finalidade de que o neno entenda perfectamente que o que vai ser dito a continuación vai dirixido expresamente a el; a continuación, a profesora pregúntalle (1. 85) que está sucedendo, por que se está erguendo. $\mathrm{O}$ neno non responde e despois dun par de intervencións que non teñen relación con esta chamada de atención a mestra volve tomar a quenda de palabra para indicarlle a este neno que a acción que está levando a cabo é incorrecta (1. 88); en canto se decata, porque o neno sinala a dirección que toma (ir ao lavabo), do seu erro rapidamente, a través dunha estratexia de cortesía negativa (estratexia número 6 seguindo a listaxe feita por Brown e Levinson 1988), lexitima a este neno a continuar a súa acción. Esta corrección e lexitimización chega da man do recoñecemento de que era ela quen estaba errada e non o neno; o código empregado pola mestra, quen, recordemos que emprega o galego como código base, é nesta ocasión o castelán, marcando así que esta intervención é algo totalmente improvisado, fóra do guión do normal funcionamento dunha clase e marcando a distancia co seu interlocutor (Gumperz 1982).

\section{Fragmento 2: 4 anos}

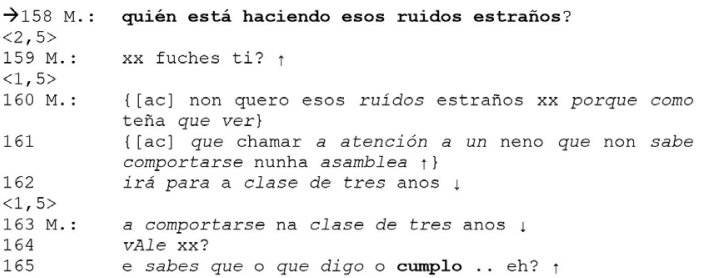

Neste segundo fragmento, continuación do anterior, a mestra comeza (1. 158) esta chamada de atención empregando o código castelán, marca de maior severidade e frialdade do momento; ademais a mestra continúa esta intervención focalizando a chamada de atención no neno en cuestión (1.159). Unha vez que retoma o control da situación a profesora continúa esta subsecuencia empregando o código galego, marca de que a formalidade volve facer acto de presenza. Ademais, fai fincapé na idea de que os nenos que non saben comportarse acorde coa idade que teñen (1. 161-163) irán para a clase dos máis pequenos, recalcando esta ameaza facéndolles saber que estas 'promesas' si que se levan a cabo, que non caen en saco roto (1. 165).

\section{- Fragmento 3: 4 anos}

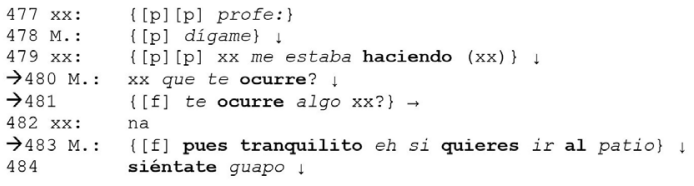

Neste fragmento podemos observar como un neno interpela á mestra (1. 477) para queixarse de que un compañeiro o está a molestar (1.479) e a profesora emprega a seguinte intervención para comezar a secuencia de chamada de atención, preguntándolle (1. 480) a ese outro neno que está sucedendo; para isto emprega unha interrogación directa, xa que a comeza co nome dese neno, para que saiba perfectamente que se 
está referindo a el e non haxa lugar a dúbidas. Seguidamente (1. 481) e cun ton máis forte, a mestra vólvelle preguntar se sucede algo, de novo focalizando a chamada de atención no neno mediante o uso do seu nome e remata a intervención cunha xuntura tonal final sostida, claro indicador de que esta secuencia non finaliza aquí. O neno comeza a dar réplica (1. 482), pero a mestra rapidamente toma de novo a palabra (1. 483) para rematar a súa chamada de atención indicándolle que se quere ir ao recreo ten que estar tranquilo; para isto emprega un ton de voz forte e unha xuntura tonal final descendente, indicador de que agora si remata esta secuencia. Na última intervención (1. 484), a profesora retoma a actividade conxunta referíndose ao neno que ten ao seu carón. Nesta secuencia e con este cambio de código tan marcado por parte da mestra (1. 480-481, 483) podemos observar perfectamente como se produce este distanciamento entre interlocutores, provocado pola profesora, para que esta chamada de atención sexa máis severa e os nenos entendan a mensaxe de que deben comportase segundo as normas establecidas ao comezo, non só deste curso, senón ao comezo da súa etapa nesta Educación Infantil.

\subsection{Exclusión do interlocutor}

No caso desta outra finalidade, a intención da mestra é excluír o seu interlocutor, o neno interpelado, do resto de nenos, que conforman o conxunto da clase e o grupo maioritario; o obxectivo desta táctica da mestra é facerlle ver ao neno que co seu comportamento non pertence ao resto da clase, que si se comportan correctamente.

- Fragmento 4: 4 anos

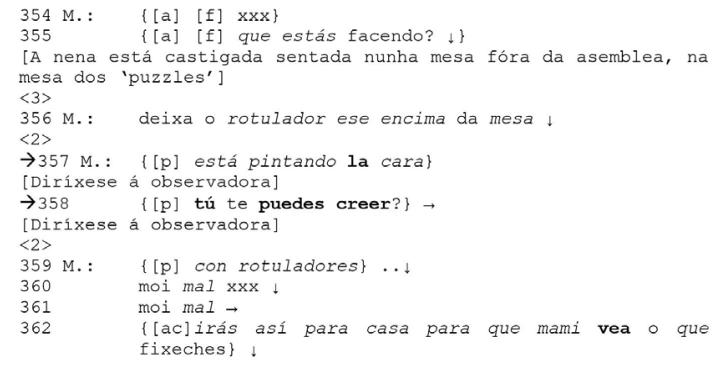

Nese novo fragmento unha nena está castigada, sentada nunha mesa na parte de atrás da aula e a mestra detecta que continúa comportándose mal, polo que comeza a chamarlle a atención (1. 354-355) empregando un ton forte e agudo; como a nena segue sen facer caso desta advertencia, a profesora continúa coa chamada de atención (1. 356) indicándolle que ten que deixar o obxecto que ten na man enriba da mesa que ten diante. Despois dunha breve pausa, a mestra diríxese, nas seguintes tres intervencións (1. 357-359), á observadora empregando o código castelán e un ton máis piano para manifestar a súa sorpresa sobre o que esta nena estaba facendo: pintando a cara cun rotulador, a pesares de estar castigada polo seu mal comportamento anterior. A continuación a mestra emprega dúas quendas de fala (1. 360361) para subliñarlle á nena que o que acaba de facer está mal, que non se pode facer, empregando a fórmula de adverbio de cantidade máis adverbio de modo negativo (moi mal); na primeira destas intervencións a profesora focaliza a chamada de atención usando o nome da nena e na segunda delas só a fórmula negativa desta combinación de adverbios. Finaliza esta subsecuencia cunha intervención (1. 362) na que recalca que esta nena irá para casa así pintada para que os pais vexan que se comportou mal, coa posibilidade de que eles tamén lle chamen a atención, en reforzo da que acaba de ter na clase.

\section{- Fragmento 5: 4 anos}

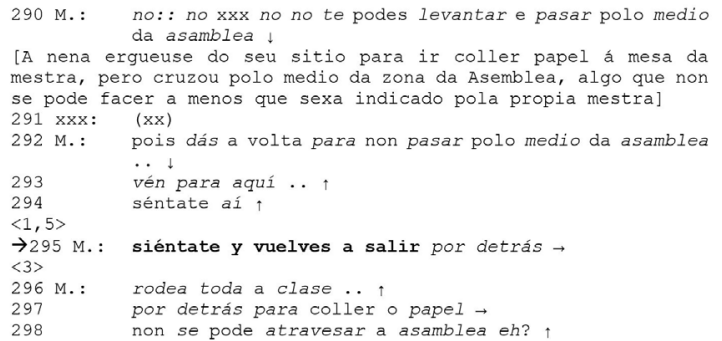

Nesta secuencia, unha nena atravesa o espazo da asemblea e a mestra rapidamente intercéptaa (1. 290); esta nena comeza a replicar (1. 291), pero seguidamente a profesora explícalle (1. 292-294) como debe facer para levar a cabo a súa acción. A continuación deixa pasar unha breve pausa e, como a nena non responde debidamente, a mestra fai tomar distancia á nena sobre os demais compañeiros mediante ese cambio de código (1.295) e a través dunha imposición que remata nunha xuntura tonal final sostida. Despois ten lugar unha pausa maior que a anterior e a mestra retoma esta chamada de atención para volver explicarlle (1. 296298) á nena como debe facer; finaliza a súa intervención cunha pregunta de confirmación da información seguida dunha xuntura tonal final ascendente que remarca máis a información que a mestra está dando. 


\subsection{Marcador da intensidade}

Ao empregar o cambio de código para marcar a intensidade, a mestra consegue facer fincapé en aspectos de comportamento importantes; ademais, emprega outras marcas reforzadoras, como poden ser as formas diminutivas, sobre todo en castelán, así como as formas ditongadas dos reforzos das imaxes positivas dos nenos.

\section{- Fragmento 6: 4 anos}

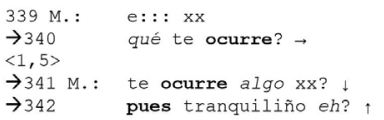

Nesta nova secuencia a situación é similar a unha vista anteriormente, debido a que un neno se está comportando de forma inadecuada e a mestra debe interromper a clase para chamarlle a atención, comezando por focalizar nel esta subsecuencia (1. 339) e continuando cunha pregunta directa (1. 340) en castelán e mais cunha xuntura tonal final sostida, claro indicador de que esta chamada de atención vai continuar. Despois dunha breve pausa e ante o silencio do neno, a mestra repite a pregunta anterior, de novo en castelán (1.341) e reforzando esa focalización primeira. Finalmente, para rematar, a profesora indícalle ao neno que debe comportarse ben (1.342) e acaba esta intervención cunha xuntura tonal final ascendente que indica que este momento de interrupción está xa rematado.

\section{- Fragmento 7: 4 anos}

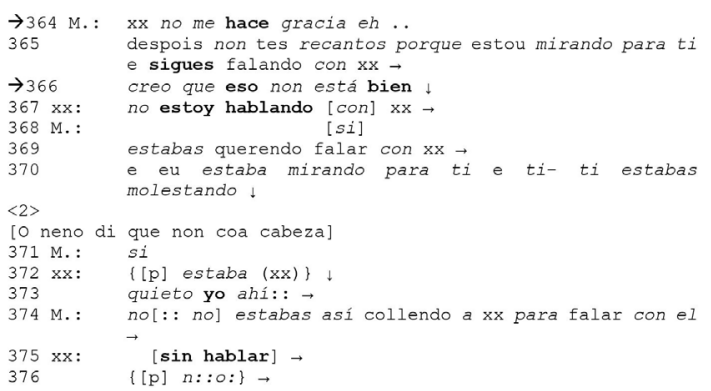

Neste novo fragmento, pertencente ao curso de 4 anos, hai un neno que está falando cun compañeiro mentres deben estar en silencio para realizar unha das actividades conxuntas e a mestra, con anterioridade, xa lle fixo unha advertencia visual, unha mirada, pero o neno en cuestión seguiu falando co compañeiro, polo que agora a mestra interrompe a clase para comezar esa chamada de atención verbal transcrita no fragmento. Comeza nomeando polo nome propio a ese neno (1. 364), iniciando o toque de atención, e continúa (1. 365) indicándolle cal é o castigo por non se ter comportado correctamente, ademais de facerlle ver que non era a primeira vez que tiña un toque de atención; como confirmación deste feito, a mestra recalca (1.366) a idea de que ese comportamento non está ben e é aquí onde emprega ese cambio de código como marcador da intensidade da chamada de atención, ademais de acompañalo dunha xuntura tonal final descendente. $\mathrm{O}$ neno dálle unha réplica (1.367) á mestra, pero esta rapidamente corta ese comentario (1. 368), mesmo solapando ao neno, e retoma a quenda de fala para, nas dúas seguintes intervencións, explicarlle novamente (1. 369-370) que si estaba facendo aquilo polo que lle foi chamada a atención. Despois dunha pausa e de que o neno responda negativamente cun movemento de cabeza, a mestra volve confirmar (1.371) que si se deu a situación que ela describiu anteriormente e o neno, de novo, volve darlle réplica (1. 372), pero esta vez achega un argumento expansivo (1.373) a esta contestación, pero á mestra non lle importa e continúa (1. 374) explicándolle que se estaba comportando mal, mesmo dicíndolle exactamente que era o que estaba a facer. $\mathrm{O}$ neno, que foi interrompido, intenta finalizar a súa argumentación (1. 375-376), pero a profesora non presta atención e decide retomar a actividade conxunta que estaban realizando, dando por finalizada así esta secuencia de chamada de atención.

- Fragmento 8: 4 anos

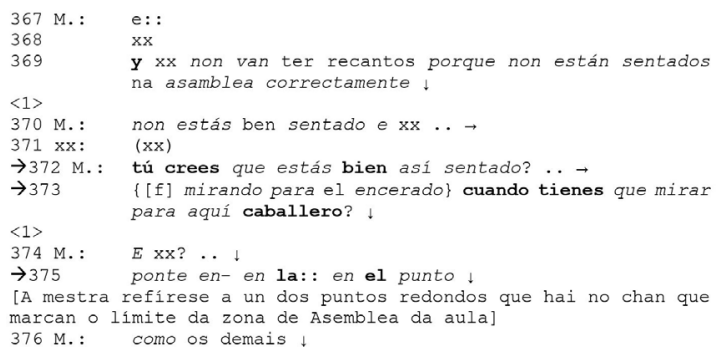

Nesta secuencia a mestra debe interromper a actividade conxunta debido a que dous nenos se están comportando mal; emprega, polo tanto, as primeiras quendas de fala (1. 367-369) para sinalar que dous nenos son os focalizados, mediante os seus nomes propios, e explica o motivo desta chamada de atención. Despois dunha breve pausa, a mestra continúa remarcando (1. 370) o feito de que non estaban ben sentados e un dos nenos dálle réplica (1. 371), aínda que na gravación non se pode entender o suficiente 
como para transcribilo; seguidamente, a mestra retoma a quenda de fala e nas seguintes dúas intervencións (1. 372-373) verbaliza a chamada de atención con eses cambios de código que contribúen a marcar a intensidade dese toque de atención, con esas formas en castelán (tú / crees / bien / cuando / tienes / caballero), que lle outorgan máis forza ao discurso da mestra. A continuación ten lugar unha breve pausa de novo e a profesora retoma a palabra (1. 374) preguntándolle a un dos nenos se entendeu esa chamada de atención e continúa na seguinte intervención (1. 375) indicándolle que debe facer, onde debe colocarse, novamente cun cambio de código que vén dado, principalmente, por eses artigos determinados en castelán (la : : / el). Finaliza a mestra esta secuencia coa observación de que os compañeiros están ben sentados (1. 376), como advertencia de que tome nota do comportamento dos demais que o están facendo ben.

\section{- Fragmento 9: 4 anos}

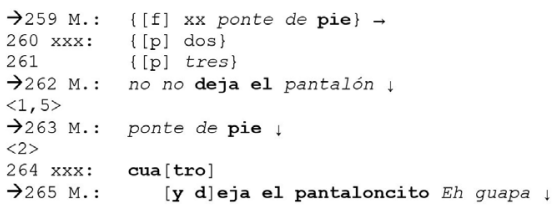

Nesta nova secuencia a mestra comeza a chamada de atención (1. 259), mentres unha nena continúa a realizar a tarefa conxunta (1. 260261); a profesora, na seguinte intervención (1. 262) emprega este cambio de código para remarcar a chamada de atención e acompáñaa dunha xuntura tonal final descendente que lle confire un carácter máis serio. Despois dunha breve pausa, a mestra retoma a quenda de fala (1. 263) para continuar a chamada de atención que volve finalizar cunha xuntura tonal final descendente; a continuación deixa unha nova pausa, esta vez algo maior que a anterior, e, despois dunha intervención da nena que segue a facer a tarefa conxunta (1.264), a profesora intervén (1. 265) para remarcar esa chamada de atención mediante o cambio de código do galego ao castelán. Ademais, nesta mesma intervención existen outros indicios de contextualización que axudan a reforzar esa chamada de atención, como son o emprego da forma diminutiva, en castelán, da peza de roupa de vestir á que fai referencia (pantaloncito), o ton elevado da seguinte palabra $(E h)$ e mais a xuntura tonal final descendente, que remarca ese carácter serio e formal de toda esta secuencia analizada.
- Fragmento 10: 5 anos

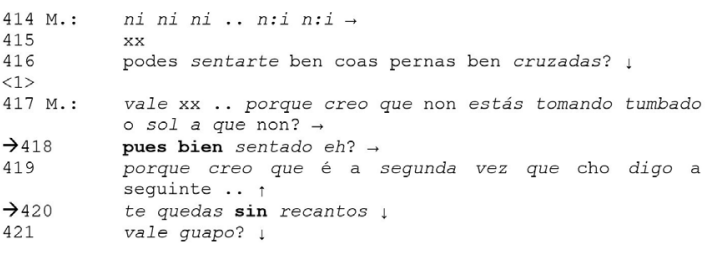

Nesta secuencia, pertencente ao curso de 5 anos, están realizando a actividade conxunta referida a propoñer palabras que comecen por unha sílaba determinada, como indica a mestra na primeira intervención (1.414) e un neno compórtase mal, polo que a actividade queda interrompida polo inicio dunha chamada de atención, que comeza coa focalización nese neno por parte da mestra, que emprega o seu nome propio (1.415) para marcar máis esta secuencia. Na seguinte intervención (1.416) a profesora pídelle ao neno que sente segundo as normas da clase mediante unha pregunta cunha xuntura tonal final descendente e, despois dunha breve pausa, a mestra retoma esta chamada de atención (1. 417) indicándolle ao neno que o seu comportamento, a súa forma de estar sentado, non é o correcto para estar na clase. Para facer fincapé nesta idea, a profesora reforza esta intervención co emprego de dúas palabras en castelán (1.418) que axudan a marcar a intensidade da chamada de atención (pues bien). A continuación a mestra continúa explicando que esta situación non é a primeira vez que se dá nesta xornada escolar e despois volve remarcar o aviso de castigo (1.420) e, de novo, temos un cambio de código e mais unha xuntura tonal final descendente, que reforza aínda máis este carácter serio que imprima todo este tipo de secuencias. A profesora finaliza esta interacción cunha pregunta de confirmación da información (1. 421) seguida dun apelativo que, neste caso, lle resta un grao de seriedade á chamada de atención.

\subsection{Préstamos frecuentes}

A excepción do fragmento anterior (fr. 10), no curso de 5 anos o que sucede é que o número de chamadas de atención baixa drasticamente (recordemos que son 34 fronte a 18) e a mestra xa non emprega tantas estratexias de cambio de código coas finalidades analizadas nos apartados anteriores, senón que neste curso esas chamadas de atención son máis puntuais e focalizadas, cun par de intervencións simplemente.

Ademais, neste curso, a mestra emprega palabras en castelán de forma máis illada; utiliza 
préstamos frecuentes, termos que son habituais para ela á hora de dar clase, no seu discurso. Entendemos por préstamo aquelas palabras pertencentes a un código que son inseridas no código base da fala. Ademais, estas formas castelás que emprega a mestra soen ser de uso frecuente na fala oral dos galegos, como son 'ahora', 'despierta' ou 'ustedes'. Cabe remarcar que a mestra emprega sempre estas palabras en castelán e non en galego, de aí a consideración que lles outorgamos de préstamos.

\section{- Fragmento 11: 5 anos}

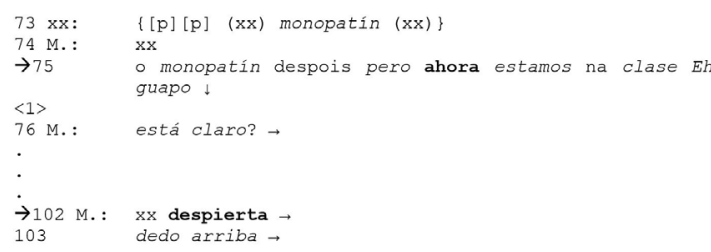

Nesta secuencia, a mestra cháma a atención a un neno (1. 75) que estaba xogando cun monopatín e no medio da súa intervención emprega un deses préstamos dos que estabamos a falar (ahora) para remarcar que este non é o momento de que o neno estea con ese obxecto na man e que ten que atender ao que están facendo os demais. Máis adiante, nesa mesma gravación, outro neno está despistado e non segue o ritmo da clase, da actividade conxunta, neste caso concreto a realización no aire da pictografía do nome do encargado, polo que a mestra lle chama a atención (1. 102) empregando esa forma castelá (despierta) que, ademais, posúe un ditongo que axuda a reforzar esa chamada de atención. Remata a mestra esta intervención cunha xuntura tonal final sostida e agrega, na seguinte quenda de fala (1. 103), unha instrución breve e concisa do que debe facer o neno para seguir o ritmo da clase.

\section{- Fragmento 12: 5 anos}

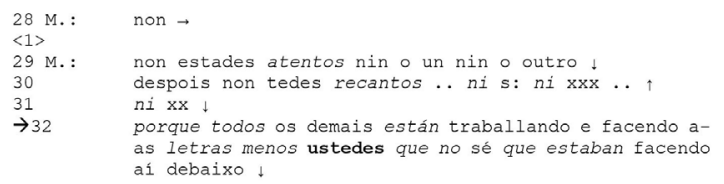

Nesta última secuencia coa que amosar estes préstamos de uso frecuente por parte da mestra no curso de 5 anos, hai dous nenos que non están prestando a atención esixida e a profesora comeza a chamada de atención (1. 28) cunha negación rotunda para, despois dunha breve pausa, continuar a expansión desta subsecuencia explicándolles a eses dous nenos que non estiveron atentos (1. 29) e polo tanto cal vai ser o castigo desa desobediencia, remarcando, mediante o emprego dos seus nomes propios, a que nenos en concreto se está referindo (l. 30-31). Na seguinte, e última, intervención da mestra (1. 32), temos unha explicación máis ampla da situación, de que eses nenos non se estaban comportando como deberían poñendo como exemplo de bo comportamento aos demais compañeiros e focalizando que eran estes dous os que non cumprían mediante o emprego desa forma prestada doutra lingua (ustedes), ademais de acompañar esta explicación dunha xuntura tonal final descendente, que sempre marca máis esa seriedade que este tipo de secuencias teñen.

\section{Conclusións}

No curso de 4 anos existe unha maior cantidade de cambio de código e, polo tanto, das finalidades do mesmo, xa que a mestra debe manter máis a orde na clase e marcar máis claramente as intencións de cada unha destas secuencias; os nenos son máis pequenos e o seu tempo de atención menor que no curso seguinte, polo que a profesora debe estar máis atenta e ser menos permisiva coas interrupcións do normal desenvolvemento da xornada. De aí que a meirande parte das chamadas de atención teñan lugar neste curso escolar de 4 anos (2015-2016).

Pola contra, no seguinte curso de 5 anos (2016-2017) redúcese o número de chamadas de atención (18 fronte ás 34 do ano anterior) e o que aparece é un maior uso dalgúns préstamos típicos da fala desta mestra, en detrimento do cambio de código do curso de 4 anos. Isto pode deberse a que a profesora neste curso non precisa manter tanto control sobre o comportamento dos nenos e relaxa a súa fala, facéndoa máis espontánea. Ademais, os préstamos que aparecen no seu discurso son préstamos moi xeneralizados na produción oral relaxada dos falantes galegos.

A conclusión xeral que tiramos destes datos é a evolución no comportamento dos nenos que, a medida que avanza o tempo, reciben menos chamadas de atención, polo que deducimos que o seu comportamento é mellor, van sendo máis autónomos e van comprendendo mellor, dende o comezo do curso, cales son as normas para estar correctamente nunha aula, evitando así a aparición desas chamadas de atención por parte da mestra e, como consecuencia, protexendo as súas imaxes positivas fronte ao resto de compañeiros. A principal recompensa que obteñen estes nenos é ser tratados como nenos maiores, obxectivo moi presente no imaxinario común destes nenos. 


\section{Referencias bibliográficas}

Brown, Penelope e Levinson, Stepehn C. (1988): Politeness: some universals in language usage. Cambridge: Cambridge University Press.

Díaz-Ferro, Marta (2018): "Socialización bilingüe infantil en Galicia: o uso de diminutivos galego-castelán na aula de 4 anos", en M. Díaz Ferro, J. Diz Ferreira, A. Pérez Pérez e A. Varela Suárez (coords.), Novas perspectivas en Lingüistica Aplicada. Lugo: Axac, pp. 221-230.

Duranti, Alessandro; Elinor Ochs e Bambi B. Schieffelin (eds.) (2014): The Handbook of Language Socialization. Malden: Blackwell Publishers.

Ely, Richard e Jean Berko Gleason (1996): "Socialization across Contexts", en P. Fletcher e B. MacWhinney (eds.): The Handbook of Child Language. Oxford: Blackwell Publishers, pp. 251-270.

Grosjean, François (2010): Bilingual. Life and reality. Cambridge: Harvard University Press.

Gumperz, John J. (1982): Discourse strategies. Cambridge: Cambridge University Press.

Kulick, Don e Bambi B. Schieffelin (2006): "Language socialization", en A. Duranti, E. Ochs e B. B. Schieffelin (eds.), A Companion to linguistic anthropology. Malden: Blackwell Publishers, pp. 349-368.

Ochs, Elinor e Bambi B. Schieffelin (1995): "The impact of language socialization on grammatical development", en P. Fletcher e B. MacWhinney (eds.): The Handbook of Child Language. Oxford: Blackwell Publishers, pp. 73-94. 